\title{
LAS CLAVES HERMENÉUTICAS DEL PENSAMIENTO DE RAMÓN LLULL
}

\author{
Sebastià Trías Mercant \\ UNED. Palma de Mallorca
}

\section{RESUMEN}

Una de las graves dificultades para entender la filosofía de Ramón Llull es fijar las claves hermenéuticas de su pensamiento. Unos han valorado excesivamente sus formación latino-escolástica. Otros han buscado sus raíces arábicas. El presente artículo hace una revisión crítica de la bibliografía al respecto y considera que la formación científica del pensamiento luliano, siempre fuera del marco universitario de su época, es el resultado del contacto con la lengua y la ideología de ls musulmanes de la post-conquista de Mallorca, de la lectura directa o indirecta de textos latinos y de su presencia en las escuelas de Medicina de Montpellier.

Palabras clave: Llull, musulmanes, hermenéutica, pensamiento

\begin{abstract}
The hermeneutic keys of Ramon Llull's thought. One of the greatest difficulties to understand Ramon Llull's philosophy is its hermeneutic approach to his thought. Some have valued extremely his latin scholastic Studies, others have searched for his Arab background. This article gives a critical review of his bibliography with regard to the subject under discussion and takes into account that the scientific knowledge of Ramon Lull's thought was never part of the university world of his time.It is the result of the close union with the language and the Arab ideas during the post-conquest days in Mallorca, the acquisition of first and second hand information of latin texts and his presence at Montpellier's Medicine schools.
\end{abstract}

Key words: Llull, Moslem, hermeneutic, thought

\section{STATUS QUAESTIONIS}

Las claves hermenéuticas del pensamiento luliano deben buscarse en el encuentro lingüístico de tres culturas ${ }^{1}$ en el marco de convivencia, durante un tiempo y un espacio relativamente reducidos, de las religiones judía, cristiana y musulmana. ${ }^{2}$ Convendría retomar esta idea y replantearla

1 S. Trías Mercant, Història del pensament a Mallorca, 1985, vol. I, pp. 17-40.

2 S. Trías Mercant, «La filosofía de Ramón Llull, encuentro de lenguas», en Actas del V Congreso Internacional de Filosofía medieval, 1979, vol. II, pp. 1311-1317. 
otra vez desde la llamada perspectiva de la formación científica de Ramon Llull o, como se ha dicho también, de las fuentes de la obra luliana.

No cabe duda, de que Llull personaliza el encuentro de la cultura cristiana con las culturas islámica y judía, tal como aparece en una de sus primeras obras, el Libre del gentil e dels tres savis (1274-1276).

No obstante, desde posturas anti o pro Llull se ha llegado a soluciones divergentes. Las primeras, recogiendo la tesis del dominico polaco Bzowski (1618), han sostenido la existencia de fuentes árabes en la teología luliana. Por el contrario, las segundas, con el fin de contrarrestar las acusaciones de los dominicos sobre la heterodoxia de Llull, han intentado esconder las influencias árabes y presentan el pensamiento luliano perfectamente integrado en la patrística y la escolástica cristianas. ${ }^{3}$

Los lulistas de finales del siglo XIX y comienzos del XX, declarados defensores de Ramón Llull, se han alineado bien a favor de una dependencia arabista de las doctrinas lulianas Ribera, Asín, Tusquets) o, por lo menos, a favor de una presencia de fuentes árabes en las obras de LLull (Menéndez Pelayo, Mateu Obrador), bien, por el contrario, recelosos todavía de las polémicas de siglos anteriores, se han manifestado en contra, reconociendo en todo caso únicamente una cierta coincidencia formal entre el pensamiento árabe y el luliano (Bové, Probst, Longpré, Eijo Garay, Sureda Blanes).

La hermenéutica actual busca una mayor objetividad mediante el análisis crítico de las obras lulianas. Centra la atención en las citas de autores y de obras que Llull aduce, ya que en ningún caso sigue un modelo exclusivo. Establece también un estudio comparado de las doctrinas que expone con las de otros autores conocidos.

Las citas directas de autores aparecen ocasionalmente en las primeras obras lulianas, ${ }^{4}$ cosa que ha hecho pensar en lecturas más o menos directas del autor durante la etapa de formación ${ }^{5} 0$ en un empacho más tardío y atropellado, con el fin de hacer frente por necesidad a ciertas corrientes, como, por ejemplo, la escolástica parisina. ${ }^{6}$

Las citas indirectas o indefinidas, que aparecen también en las obras de Llull, han movido a la crítica a buscar las posibles fuentes de referencia. En el Llibre del gentil declara Llull que la obra fue escrita siguiendo la manera del libro arábico «Del gentil» y en el Liber de fine recomienda la lectura de los libros de Alchindi y de Telif. En el primer caso se ha sugerido la la posibilidad del Kitab al-khasari de Judà Haleví, pese a las grandes diferencias ${ }^{7}$, gracias a las similitudes, del Liber super Psalmum «Quicumque vult», otra de las obras lulianas. ${ }^{8}$ Las recomendaciones del Liber de fine parecen coincidir, respectivamente, con los tratados Risalat al-Kindi y Contrarietas alfolica. ${ }^{9}$

3 R. Pasqual, Vindiciae Lullianae, Avenione, 1778, vol. II, pp. 796-812.

4 Ibídem, vol. I, p. 72. T. y J. Carreras Artau, Historia de la Filosofía española. Filosofía cristiana de los siglos XIII al XV, Madrid, vol. I, p. 268. F. Sureda Blanes, «Franciscanisme i lul.lisme», La Nostra Terra, 8 (1935), pp. 243-260.

5 S. Garcías Palou, La formación científica de Ramón Llull, Inca, Mallorca, 1989.

6 A. Bonner, Selected Works of Ramon Llull, Princeton University Press, 1985; trad. cat. Palma de Mallorca, Moll, 1989, vol. I, p. 18.

7 J.M. Millas Vallicrosa, «Introducción» a la ed. crítica del Libre predicationis contra judeos, Madrid-Barcelona; 1957, p. 23.

8 Bonner, o.c., p. 92.

9 Ch. Lohor, «Ramon Llull, Liber Alquindi and Liber Telif», Estudios Lulianos, XII (1968), pp. 145-160. 
A veces - en el Llibre de contemplació, Doctrina pueril, y los Començaments de medicina, obras de la primera etapa, cita Llull obras concretas, como el caso de diez obras de Aristóteles. En obras de época más avanzada, como en el Liber de convenientia fidei et intellectuis in objecto (1309), Llull se refiere concretamente a la Summa contra gentiles de santo Tomás y al De Trinitate agustiniano.

Ignoramos si Llull conocía directamente los autores clásicos, cristianos y árabes que cita. Desconocemos también, en el caso de ser lecturas indirectas, cuándo y por qué conductos llegaron estos autores al conocimiento de Llull. Parece ser que Algazel fue el único autor que Llull conoció directamente, tanto desde una dimensión lógica como teológica. ${ }^{10}$

El análisis comparado de las doctrinas pone de manifiesto que Llull sólo conoce sumariamente las distintas direcciones del pensamiento filosófico-teológico de su época y las formulaciones de las cuestiones debatidas en su tiempo, sin adentrarse en distinciones más o menos precisas, en controversias suscitadas entre escuelas o las distintas posiciones sobre una cuestión. ${ }^{11}$ No debemos olvidar que Llull no buscaba apoyos teóricos para formar doctrina o proponer un sistema filosófico. Estaba interesado en crear un arte eminentemente práctico para descubrir la verdad como base de las otras prácticas de conversión y salvación. ${ }^{12}$

De todas formas, el ámbito de las doctrinas descubre un mayor campo de dependencias, influencias o encuentros ideológicos. Las relaciones de Llull con la teología agustiniano-anselmiana, y en especial con la escuela franciscana, han sido ampliamente debatidas (los estudios de Probst, Sureda Blanes, Longpré, Carreras Artau, Platzeck y Garcías Palou, pueden verse a través de Oliver ${ }^{13}$ y de González Caminero ${ }^{14}$ ),así como también sus vinculaciones con la literatura polémico-apologética de su tiempo. ${ }^{15}$

Tanto las citas como las dependencias doctrinales carecen de sentido si no se integran en la biografía y en el ámbito cultural propio de Ramón Llull. La investigación actual es cada vez más consciente de que, al menos en el primer LLull, este ámbito cultural se centra en la Mallorca de las tres religiones de la post-conquista, en el Studium arabicum que los dominicos tenían en la ciudad de Mallorca y, a través de él, quizás también, en las bibliotecas mallorquinas del monasterio cisterciense de La Real y de los conventos de San Francisco y de los carmelitas y, sobre todo, en la polifacética y científica Montpellier.

10 A. Cortabarría, «Connaissance de l'Islam chez Raymond Lulle et Raymond Martin, O.P. Parallèle», en «Raymond Lulle et le Pays d'Oc», Cahiers de Fanjeaux, 22 (1987), pp. 33-56.

11 J. Stohor, «Las rationes necessariae de Llull a la luz de las últimas obras», Estudios Lulianos, XX (1976), pp. 5-52 (p. 18).

12 R. Pring-Mill, (1955-56) «The Trinitarian World Picture of Ramon Lull», Romanisches Jahrbuch, VII (1955-56), pp. 229-256 (p. 230).

13 A. Oliver, «El Beato Ramón Llull en sus relaciones con la escuela franciscana de los siglos XIII-XIV», Estudios Lulianos, IX (1965), pp. 15-70; X (1966), pp. 47-55; XI (1967), pp. 89-119; XIII (1969), pp. 51-65.

14 N. González Caminero, «El puesto de Ramón Llull en la filosofía cristiana», Estudios Lulianos, VII (1963), pp. 19-51.

15 Carreras Artau, o.c., vol. I, pp. 335-344, y R. Sugranyes, «Ramon Llull, docteur des missions», Studia Monographyca et Recensiones, V (1950), pp. 3-44. 


\section{EL CONTEXTO BIOGRÁFICO-CULTURAL DEL PENSAMIENTO LULIANO}

La Vita coetanea ${ }^{16}$ escrita en 1311 por un religioso de la cartuja de Vauvert siguiendo las indicaciones que el mismo Llull había hecho durante su estancia en aquel monasterio, aporta breves pero suficientes datos para esbozar las líneas maestras.

Ramon Llull —cuenta la Vita-, después de su transformación vital decide dedicar su vida a la conversión de los sarracenos. Para ello piensa escribir un libro contra sus errores. Es consciente, sin embargo, de su deficiente formación para una empresa tan grande, ya que sólo había aprendido un poco de gramática. ${ }^{17}$ Por ventura, la gramática de la lengua familiar, que, si bien le servía para entenderse con los esclavos musulmanes de la post-conquista de Mallorca, ${ }^{18}$ era insuficiente para el conocimiento doctrinal de la teología islámica y de la teología cristiana. Le urgía, pues, una formación científica, que discurrió, según deja entrever la Vita, según tres ejes ideológicos básicos:

1. Un eje latino-escolástico. Siguiendo los consejos de Ramón de Penyafort, Llull no va a París, sino que aprende gramática (latina) en su ciudad natal. ${ }^{19}$ Entre 1265 y 1274 acude alternativamente a «una abadía cercana a la ciudad», donde empieza a escribir aquel libro que primero llamó Ars major y después Ars generalis ${ }^{20}$ y «sube a una montaña no lejos de su casa en la que le aparece un joven pastor, quien, al ver los libros que había escrito, le bendice con «bendiciones proféticas».

La tradición lulista asocia la formación latino-escolástica de Llull con el monasterio cisterciense de La Real, ya que así podía explicar el anacronismo doctrinal, el agustinismo, cierto antiaristotelismo y, quizás también, la dimensión mística del pensamiento del primer Llull.

Sin embargo, después de los trabajos de Hillgarth sobre la biblioteca de La Real, ${ }^{21}$ esta tradición regalense se ha sometido a crítica. El monasterio cisterciense carecía de escuela monacal y poseía una reducida biblioteca, entre cuyos volúmenes no aparecían las grandes obras de san Agustín, de Ricardo de San Víctor y de san Anselmo ni la Summa de santo Tomás ni los escritos de san Alberto el Grande. En definitiva, faltaban en la biblioteca de La Real aquellas obras que pudieran sirvir a Llull para redactar el Llibre de contemplació y la Art abreujada d'atrobar veritat.

16 Edición crítica de Baudin de Gaiffier en Analecta Bollandiana, XLVIII (1930), pp. 146-175. Reproducción de M. Batllori en Obras literarias, BAC, 1946, pp. 46-76. Nueva edición crítica de H. Harada en Raimundi Lulli Opera Latina, VIIII, 1980, pp. 271-309. En adelante citaré esta obra con las siglas ROL.

17 ROL, VIII, p. 275.

18 G. Rossello y J. Sastre, «El mudejarismo en Mallorca en la época de Ramón LJull», Boletín de la Sociedad Arqueológica Luliana, XXXIX (1982), pp. 257-263.

19. ROL, VIII, p. 278.

20 Ibidem, p. 280. Ars major es un subtítulo de la primera obra del Arte o Ars compendiosa inveniendi veritatem. Ars generalis, en cambio, es el nombre genérico que, a partir de 1294, usa Llull para referirse a su sistema artístico, pese a que ninguna obra concreta lleve ese título, excepto Ars generalis ultima (1308). Para un mayor esclarecimiento de estas cuestiones bibliográficas, véase A. Bonner, «Notes de bibliografia i cronologia lul.lianes», Estudios Lulianos, XXIV (1980), pp. 71-86.

21. J. Hillgarth, «Una biblioteca cisterciense medieval: La Real (Mallorca)», Analecta Sacra Tarraconensia, XXXII (1959), pp. 89-191, y «La Biblioteca de La Real: Fuentes posibles de Llull», Estudios Lulianos, VII (1963), pp. 229-259. 
Este panorama permite formular la hipótesis de que Llull pudiera leer alguna de las obras latino-escolásticas en el Studium dominicano y en las bibliotecas de los conventos de San Francisco y de los carmelitas de la ciudad de Mallorca. ${ }^{22}$

2. Un eje arábico-islámico. Llull confiesa que ignoraba la lengua arábica, propia de los sarracenos, ${ }^{23}$ que adquirió un esclavo moro para que se la enseñara ${ }^{24}$ y que solicitó y consiguió del rey la fundación del monasterio de Miramar (1276) para que trece frailes franciscanos aprendieran el árabe. ${ }^{25}$

En 1260 Ramón Martí había escrito la Summa contra els errors de l'Alcorà y diez años después Tomás de Aquino, a petición de Ramón de Penyafort, escribe la Summa contra gentiles. La aplicación de la metodología apologética incluida en estas obras resultó un fracaso, cuando en 1268-69 Ramon Martí intenta aplicarla para convertir al sultán al-Mustansir de Túnez. Del hecho de que Llull se refiera con cierto tono de crítica a este suceso algunos comentaristas han deducido una condena luliana a los métodos dominicanos y una clara indicación de que su Arte podría superar las dificultades de aquellos.

Sin embargo, esta actitud crítica de Llull corresponde mas bien a una etapa de madurez, ya que su primera formación apologética pudo ser dominicana y coincidía con el perfil de la política expansionista y pacifista de Jaime I, mediatizada por su confesor Ramón de Penyafort: estudio del árabe por parte de los cristianos y composición de ciertos «tratados» que abordaran aquellas cuestiones de las que los futuros misioneros tendrían que servirse en su actividad apologética. En cumplimiento de estos criterios, la orden dominicana había abierto, en torno a 1242, una serie de «escuelas de lenguaș» en Mallorca, Valencia, Barcelona, Murcia y Játiva. En ellas el aprendizaje del árabe se completaba con una formación doctrinal que incluía el conocimiento del islam, de la vida de Mahoma y del Corán. ${ }^{26}$ Esta iniciativa facilita, por una parte, el diálogo con el islam e incorpora al patrimonio de Occidente el capital cultural que ofrecen los árabes españoles. Por otra, este diálogo se lleva a cabo en Cataluña y Mallorca desde el pensamiento cristiano parisino, introducido por Miguel Fabra, predicador de la Corte de Jaime I.

3. Un eje científico-filosófico. En obras posteriores Llull deja claro que la conversión de los musulmanes había de empezar por los miembros más cultos de su sociedad, a los cuales seguirían sin grandes dificultades el pueblo en general. Exigía, pues, un conocimiento bastante profundo de la teología musulmana y de la ciencia árabes, además de la teología cristiana.

Advertimos por el libro IV del Llibre del Gentil que los conocimientos que tenía Llull de la religión musulmana eran buenos. Sabemos que conocía las obras médicas de Avicena, que posiblemente leyó en una traducción latina de los círculos médicos europeos de la época. ${ }^{27}$ Sabemos también que el único autor islámico con el que tomó contacto directo del árabe fue Algazel. ${ }^{28}$

\footnotetext{
22 Garcías Palou, o.c., pp. 19-28 y 91-98.

23 ROL,VIII, p. 275.

24 Ibidem, p. 278.

25 Ibídem.

26 L. Robles, «El Studium Arabicum del capítulo dominicano de Toledo de 1250», Estudios Lulianos, XXIV (1980), pp. 23-47.

27 Garcías Palou, o.c., pp. 141-143.

28 Ch. Lohor, «Ramón Llull: Christianus arabicus», Randa, 20 (1987), pp. 7-31. Es una traducción del artículo «Christianus arabicus cuius nomen Raimundus Lullus», Freiburg Zeitschrift für Philosophie und Theologie, 31 (1984), pp.
} 
Este conocimiento no pudo adquirirlo LLull en la Escuela de lenguas dominicana de la ciudad de Mallorca. De ahí que los lulistas piensen en la presencia de Llull en Montpellier.

Dice la Vita que, después de la ilustración de Randa, el rey de Mallorca, teniendo noticia de los excelentes «libros» de Llull, lo requirió en Montpellier (1275) para que fueran examinados por un fraile. Este fraile calificó aquellos obras, principalmente unas «meditaciones» para todos los días del año, ${ }^{29}$ como obras «llenas de profecía ${ }^{30}$ y devoción católica.

En Montpellier pudo encontarse Llull, según Hillgarth, con Arnau de Vilanova, defensor del ideal franciscano en la línea de los espirituales valencianos, amparados por la casa real mallorquina, y con todo un pensamiento científico-filosófico. La influencia científica de Montpellier en la filosofía natural y en la medicina lulianas es indiscutible, ${ }^{31}$ así como la importancia de las escuelas de derecho, lógica, gramática y teología de esta ciudad.

Los «libros» que el pastor de Randa alabó y el fraile de Montpellier revisó eran, según se deduce de la Vita, el Llibre de contemplació (1273-74) y la Art abreujada d'atrobar veritat (Mallorca, 1274-75). Pero, podrían ser,a demás, todos los escritos entre 1271 y 1276, es decir, el Compendium logicae Algazelis (Montpellier, 1271-72), la Ars notatoria (1274-76), la Doctrina pueril (1274-76) y el Llibre del gentil e dels tres savis (1274-76). Excluimos los cuatro Libri principiorum, por estar datados entre 1274 y 1278.

Un análisis superficial de las seis obras citadas muestra algunos rasgos típicos del pensamiento luliano

En primer lugar, tres constantes ideológicas que se repetirán en todo el pensamiento luliano: a) la constante contemplativo-eremítica, que favorecerá la mística, la teoría del locus amoenus, las críticas del urbanismo burgués y la defensa del pauperismo evangélico; b) la constante pedagógico-ética, base del reformismo luliano, según el cual el mortificare vitia y el vivificare virtutes comportan necesariamente el invenire veritatem; c) por último, la constante artístico-apologética, destinada a buscar un nuevo método para la conversión de los musulmanes.

En segundo lugar, una más o menos equilibrada influencià de fuentes árabes y escolástcio-cristianas y, a través de ambas, de fuentes clásicas, como Aristóteles, Tolomeo e Hipócrates. La lógica algazeliana y porfiriana, así como el kalam islámico están presentes en el primer Llull. También

57-88, que a su vez es la versión revisada de la ponencia presentada al II Congreso Internacional de Lulismo, bajo el título «lbn sab' in de Murcia y el desarrollo de la Ars Luliana», Mallorca, Miramar, 1976. Sobre el tema del Christianus arabicus, véase la posición de D. Urvoy, «L'idée de "christianus arabicus"», Al-Qautara, XV (1994), pp. 497-507. M. Cruz Hernández, El pensamiento de Ramon Llull, 1977, p. 65.

29 Clara referencia al Llibre de contemplació, que consta de tantos capítulos como días tiene el año bisiesto.

30 Después de identificar Wadding este fraile con un tal Bertrán Berenguer, Batllori lo considera un simpatizante de la corriente de los espirituales, dados a la profecía sobre el porvenir de la Iglesia y del mundo (Obres essencials [195760], vol. I, p. 40). Esta interpretación coincide con la que ofrece Oliver de la ilustración de Randa, al señalar una semejanza entre la aparición del joven pastor luliano con la iluminación similar de Joaquín de Fiore. Mi opinión, en cambio, es la de un paralelismo entre ciertos aspectos de esta escena y la tradición profética islámica, con posible origen en el sura 18 del Corán (S. Trías Mercant, «La ideología luliana de Miramar», Estudios Lulianos, XXII [1978], pp. 9-29 [p. 25]).

31 J. Gaya, «El ambiente científico de Montpellier en los siglos XIII y XVI», Estudios Lulianos, XXI (1977), pp. 59-67. M Pereira, «Le opere mediche di Lullo in rapporto con la sua filosofia naturale e con la medicina del XIII secolo», Estudios Lulianos, XXIII (1979), pp. 1-35. A. Llinares, «Raymond Lulle in Montpellier. The Recasting of the Ars Major», en «Raymond Lulle et le Pays d'Oc», Cahiers de Fanjeaux, 22 (1987), pp. 17-32. 
están presentes san Agustín, san Anselmo, Ricardo de San Víctor, Escoto Eriúgena y, a través de éste, el Pseudo-Dionisio, así como algunas tesis averroístas, aunque Llull toma contacto con Averroes y los averroístas en una etapa posterior. Pese a que estos contactos hicieron evolucionar su filosofía y le permitieron articular mejor la identidad de su propio pensamiento, el diálogo directo con el averroísta no llegó a cuajar. ${ }^{32}$

Otra vía de influencia puede venir a través del Yesirah judaico, cuya fama se había renovado en Cataluña entre 1271 y 1274 y, sobre todo, a través de la importante presencia de los judíos en Montpellier, quienes a lo largo de varias generaciones ofrecerán a la cultura occidental las traducciones de los más relevantes textos de la cultura en lengua árabe .

La descripción biográfico-cultural debe ser completada por una hermenéutica de significación.

\section{EL SIGNIFICADO DE LA ARÁBICO-ISLAMIZACIÓN LULIANA}

En torno a 1263 Llull confesaba que «ipse linguam arabicam, quae sarracenorum est propia, penitus ignorare» ${ }^{33}$ y que compró un esclavo que se la enseñara. ${ }^{34}$ Cuarenta y dos años después, en 1305, Llull no sólo se declara capaz de escribir en árabe sus obras ( Ego declaravi in pluribus libris meis in lingua arabica»), sino que, además, se considera un «christianus arabicus» ${ }^{35}$ experto en cultura musulmana («Sunt experti aliqui arabici christiani, unus inter quos possum dici»), ${ }^{36}$ hasta el punto de que algunos hablan de un LLull islamólogo.

Desde los trabajos de Asín Palacios y Julián Ribera (1899) se han sucedido las investigaciones sobre el arabismo luliano. Sin embargo, después de ciertas investigaciones interesadas en descubrir - los descubrimientos han sido parcos- una terminología arábica en ciertas obras lulianas ${ }^{37}$ y determinadas estructuras y construcciones gramaticales netamente arábicas en el texto latino de la Ars consilii ${ }^{38}$ se ha dejado de lado la discusión sobre si Llull sabía hablar y escribir en árabe (Pasqual, 1778; Longpré, 1926; A. Peers, 1929; Salvador Galmés, 1935; Carreras Artau, 1939; Garcías Palou, 1989), para centrar la investigación en la procedencia y significado del arábico-islamismo luliano.

Quizás debamos apoyar esta nueva inflexión metodológica en la propia confesión de Llull en el prólogo del Llibre del gentil, cuando afirma que «ab los infeels hajam participat long de temps ${ }^{39}$

32 R. Imbach, «Lulle and the Challenge of the Parisian Averroists», en «Raymond Lulle et le Pays d'Oc», Cahiers de Fanjeaux, 22 (1987), pp. 261-284.

33 ROL, VIII, p. 275.

34 Ibídem, p. 278. Barceló demuestra que los Llull y los Picany, parientes de la mujer de Ramón Llull, eran familias feudales dedicadas al comercio de esclavos. El caso de Llull no era, pues, extraño en su ambiente familiar (Barceló, «Per sarraïns a preïcar o l'art de predicar a audiències captives», en El debat intercultural als segles XIII i XIV. Actes de les I Jornades de Filosofia Catalana, Girona, 1989, pp. 117-132).

35 ROL, IX, p. 256.

36 Ibidem.

37 Cortabarría, o.c., p. 46.

38 ROL, II, p. 216, y ROL, I, p. 25.

39 Obres essencials, vol. I, p. 107. 
y cuando indica en el Llibre de contemplació que los objetivos fundamentales de aprender la lengua arábica son poder presentar la verdad cristiana en vocablos árabes a quienes conocen esta lengua, poder loar y bendecir a Dios en ese idioma y disponer de una terminología pertinente («coneixença dels vocables») en las disputas doctrinales con los musulmanes. ${ }^{40}$

El estudio de estas perspectivas arábico-islámicas ha obligado a los comentaristas a distinguir entre «referencias» e «influencias» arábicas en las obras de Llull. ${ }^{41}$ Las primeras, en gran medida analizadas en el apartado anterior, no implican necesariamente aceptación por parte de Llull. El estudio de las segundas, en cambio, se mueve, algunas veces todavía, en el terreno de las conjeturas, ${ }^{42}$ de los presupuestos ${ }^{43}$ o de una eventual aceptación. ${ }^{44}$

Recientemente Mikel de Epalza ha indicado que las influencias islámicas en el pensamiento cristiano medieval tienen muchas veces el sentido de «influencias no explícitas». Lo más sustancial del pensamiento escolástico del cristianismo latino -afirma - está configurado por un conjunto de aceptaciones vergonzosas o rechazos no explícitos de ideas islámicas. ${ }^{45}$ Un buen ejemplo serían las rationes necessariae en el Cur Deus homo de san Anselmo, un tema, por otra parte, eminentemente luliano.

Este ocultamiento del islamismo en el pensamiento cristiano medieval se llevó a cabo a través del neoplatonismo agustiniano. De esta manera, cualquier idea de origen musulmán, compatible con el cristianismo, podía ser aceptada y esconderse bajo la protección de un texto o de una idea de san Agustín. Podemos hablar —dice Epalza - de agustinismo avicenizante y averroizante o de islamismo agustinizante, en la medida que un pensamiento islámico, que tiene por sus orígenes gran afinidad con el cristianismo, penetra fácilmente en el pensamiento latino cristiano bajo la forma de agustinismo.

Sin llegar a la teoría del ocultamiento,, investigadores anteriores habían hablado ya de un cierto sincretismo entre islamismo y agustinismo en el pensamiento luliano. Debemos advertir, sin embargo, que se refieren a una «deuda doctrinal» agustiniana y a la presencia, únicamente lingüístico-formal, de elementos arábicos, no islámicos. Pring-Mill indicaba que, si bien Llull tuvo necesidad de formas verbales para estructurar su teoría — principalmente la doctrina correlativa -, no existe una deuda doctrinal islámica, ya que aquella doctrina es explicable suficientemente a la luz de la filosofía agustiniana. ${ }^{46}$ Jordi Gayà piensa que la teoría correlativa luliana es el resultado de la conjunción de la tradición aristotélico-escolástica con ciertos factores morfológicos árabes. ${ }^{47}$

40 Ibidem, vol. II, p. 216. Sabemos por estudios recientes que en esta época la población musulmana de Mallorca, entre esclavos de la post-conquista, musulmanes introducidos por traficantes de esclavos y musulmanes libres que trabajaban como menestrales, mercaderes y arrendatarios agrícolas, era la tercera parte del total de la población insular.

41 A. Llinares, «Références et influences arabes dans le Libre de contemplació», Estudios Lulianos, XXIV (1980), pp. 109-127.

42. R. Brummer, «L'enseignement de la langue arabe à Miramar, faits et conjectures», en Actas del II Congreso Internacional de Lulismo, 1979, pp. 37-48. Garcías Palou, o.c., pp. 12-28.

43 D. Urvoy, Penser l'Islam. Les présupposés islamiques de l'Art de Lulle, París, 1980.

44 Llinares, «Références et influences».

45 M. Epalza, «Corrents islàmics aparents i amagats a la cultura medieval», en El debat intercultural als segles XIII i XIV, pp. 107-116.

46 R. Pring-Mill, El microcosmos lul.lià, Palma de Mallorca, Moll, 1961, pp. 125-152.

47 J. Gaya, La teoría luliana de los correlativos, Palma de Mallorca, 1979. 
Ambos coinciden, sin embargo, en atribuir un carácter estructural a los correlativos -Pring-Mill habla de «factor estructurizante» y Gayà se refiere a su «carácter paradigmático»—, pero no dejan claro si el lenguaje coincide o no estructuralmente con el sentido conceptual del paradigma.

Para aclarar este problema debemos averiguar si el modus loquendi arabicus, al que nos remite tantas veces Ramon Llull, pudo articular el conocimiento mismo luliano. Más importante - escribe Cruz Hernández- «es el estudio de las estructuras del pensamiento luliano que pueden mostrar el peso de la influencia del pensamiento árabe-islámico, analizado por S. Trías Mercant en 1972 y $1987 »{ }^{48}$ Mi hipótesis a la que se refiere Cruz Hernández es la de convertir la lengua árabe, sobre todo la estructura de la acción nominal, en esquema estructural de la concepción correlativa. Existe un paralelismo innegable entre el paradigma nominal de la gramática árabe y el paradigma de los nombres correlativos lulianos, como un sistema articulado en el que todo es solidario y donde cada elemento toma su valor de la posición y conexión en la estructura significativa completa. ${ }^{49}$

No cabe duda de que el pensamiento de Llull, pese a que por su gran confianza en la razón, puede considerarse «la última gran síntesis franciscana del agustinismo aviceniano», ${ }^{50}$ se decidió por la síntesis algazeliana, cuyos factores estructurales se resumen en la unicidad de Dios, la revelación profética y la inteligencia iluminada. Desde esta perspectiva, cabe referimos a los orígenes árabes de la lógica luliana, cuyo carácter instrumental, impropio de la lógica latina de la época, es una clara imitación de los modelos árabes, que consideran la lógica un instrumento de la propedéutica teológica del kalam. De ahí también las raíces musulmanas del pensamiento filosófico-teológico luliano.

Las investigaciones más recientes huyen de caracterizaciones globales y se centran en descubrir la asimilación de elementos islámicos en las obras de Llull. Partiendo de que hoy nadie duda de la influencia de la lógica islámica en el primer Llull y de la hipótesis de que el Llull maduro continuó el estudio de las fuentes arábicas y éstas se hicieron presentes no sólo en su interpretación de la lógica aristotélica sino también en el desarrollo de la teología y del Arte en general, se examina la manera en que Llull integró diversas nociones islámicas en sus obras (Lohr, 1968, 1972, 1987, 1989; Urvoy, 1980, 1989) desde el contexto musulmán del al-Andalus (Urvoy, 1972, 1980).

Últimamente, Miguel Barceló se ha alejado de la hermenéutica filosófico-teológica y lógicolingüística y ha aportado una interpretación sociológica del arábico-islamismo luliano. El proyecto misionero luliano es èl esfuerzo por resolver el problema de la coexistencia de las sociedades cristiana y musulmana mediante la desaparición de ésta a causa de su conversión al cristianismo. Partiendo del concepto de «gestores coloniales», caracterizados por su intervención económica en la Mallorca conquistada, ${ }^{51}$ y del concepto de «filosofía de frontera», en el sentido de que la hege-

48 M. Cruz Hernández, «El símbolo del árbol en Ramon Llull e Ibn al-jat-ib’», en Studia Lullistica, Palma de Mallorca, 1989, p. 25.

49 S. Trías Mercant, Ramón Llull. El pensamiento y la palabra, Palma de Mallorca, El Tall, 1993.

50 M. Cruz Hernández, El pensamiento de Ramón Llull, p. 61.

51 R. Soto, «La población musulmana en Mallorca bajo el dominio cristiano (1240-1276)», en Fontes Rerum Balearium, II (1978), pp. 65-80, 549-564. 
monía social cristiana pretende legitimar la eliminación de la cultura islámica sometida, ${ }^{52}$ afirma Barceló que el proyecto misionero de Llull no es más que la formulación teórico-teológica de los reales procesos sociales de colonización que intentaban aplicar los gestores de la conquista en el ámbito socio-económico.

Llull —concluye Barceló- formula su proyecto en Mallorca, donde no conoce más que musulmanes esclavizados o transplantados por razones políticas y económicas, y elabora una teología de la colonización que le lleva a tratar de organizar las condiciones que la nutren. De hecho, Llull busca siempre «su» islam, el islam de los esclavos de casa. Por esta razón, cuando transplanta ese proyecto de conversión a sociedades musulmanas no dominadas, éste deja de ser eficaz y es un fracaso. ${ }^{53}$

Pese a las diferencias, el arabismo y la islamología lulianos no pueden disociarse como síntesis ideológico-lingüística para entender su pensamiento. ${ }^{54}$

\section{LA DIMENSIÓN LATINO-ESCOLÁSTICA}

La conversión de los musulmanes no sólo exigía el conocimiento de la lengua arábica y de la cultura islámica, requería también un perfecto dominio de la teología cristiana y, por tanto, de la lengua latina.

No importa entrar en la antigua polémica sobre si Llull dominaba el latín suficientemente para su uso oral y escrito, ya que es una cuestión resuelta favorablemente (Rubió i Lluch, 1911; D’Alós, 1914; Bové, 1915-16; Nicolau, 1935).

El primer trabajo serio en orden a demostrar la vinculación de Llull con la patrística greco-latina y con la escolástica medieval es el del P. Pasqual en el siglo XVIII. ${ }^{55}$ Sin embargo, Llull no está interesado en formar doctrina o formular un sistema filosófico escolástico. Su objetivo era crear un nuevo Arte para «encontrar la verdad» como base de las artes prácticas de conversión y salvación..$^{56}$ Ello le obliga a leer una amplia gama de obras y de autores que puedan servir de soporte a su idea fundamental. La conversión de los musulmanes exigía, desde la coincidencia en una teología monoteísta, la teología cristiana de la divergencia trinitaria y encarnacionista.

Esta teología de la divergencia pretendía, no el «dimittere credere pro credere» tomasiano, sino el credere pro intelligere, afianzado en la tradición del fides quaerens intellectum, cuya clave son las rationes necessariae. En su dispersión ideológica, y sin mirar a quien lo dice, Llull se acerca a Escoto Eriúgena, ${ }^{57}$ a san Anselmo y a Ricardo de San Víctor y más tarde a san Agustín, Boecio y santo Tomás de Aquino ${ }^{58}$ a través de ellos, a otros escolásticos.

52 Urvoy, Penser l'Islam, y «Nature et portée des lies de Ramon Llull avec l'univers arabe», en Aristotelica et Lulliana magistro doctissimo Charles H. Lohr, Instrumenta Patristica, XXVI (1980), pp. 415-427.

53. Barceló, o.c., pp. 127-129.

54 S. Trías Mercant, «Arabismo e islamología en la obra de Ramon Llull», La Ciudad de Dios, CCVIII (1995), pp. 125-138.

55 Pasqual, o.c.

56 Pring-Mill, «The Trinitarian World Picture of Ramon Lull», pp. $229-256$ (p. 230).

57 F. Yates, «Ramón Llull y Johannes Scotus Eriúgena», Estudios Lulianos, VI (1962), pp. 71-81.

58 Garcías Palou, o.c., pp. 29, 51, 58 y 75. 
Una vez Llull puso en pie el proyecto de conversión de los musulmanes, se percató de que la idea de unidad de la christianitas, fundamental para aquel proyecto, estaba en crisis a causa de los frentes disolventes de la disidencia cismática y de la desviación eclesiástica. "Propter defectum ecclesiae, infideles permanent in errore», escribió en la Disputatio Petri clerici et Raymundi phantastici (1311). La teología de la conversión reclama, pues, la teología unionista y la teología reformista, cosa que acercó el pensamiento luliano a la teología orientalista y a las corrientes espirituales y pauperistas.

Garcías Palou ha definido cuál era la postura de Llull respecto del cisma y cuál era su contraoferta teológica. Adoptando la tesis latina acerca de la procesión del Espíritu Santo (Liber de Sancto Spiritu, 1274-83), Llull no sólo refutaba el error primario del cisma griego, sino también las tesis básicas de la cristoloigía nestoriana y monofisita (Liber de quinque sapientibus, 1294).

La teología unionista luliana, al conceder gran importancia a los temas del Espíritu Santo y de la Iglesia, foco teórico de la disidencia, debe entenderse como una teología dialogante con los cristianos de Oriente dentro del contexto unionista del concilio de Lyon. La idoneidad espistemológica de la teología unionista luliana coincide en su base con el fundamento criteriológico de su misiología. Si el diálogo misional permite comprender el racionalismo luliano como un «instrumento de seducción» respecto de la aceptación racional de la fe cristiana y, en ningún caso, como un arma idelógica contra los errores de los infieles, la disputa con los cismáticos confirma esa misma estrategia, ya que el unionismo cristiano nunca se impone por definiciones dogmáticas, sino que se difunde mediante contrastaciones ideológicas.

La misiología contra el islam y la teología unionista lulianas adquieren sentido cuando se cierra el ciclo hermenéutico mediante la teología reformista.

El análisis del reformismo luliano discurre por tres caminos distintos, pero sucesivamente más precisos:

El primero ${ }^{59}$ está dominado por el criterio de la ortodoxia. Preocupa evidenciar el alejamiento de Llull de cualquier reformismo heterodoxo, para integrarlo en el seno del espíritu de reforma de la Iglesia católica. Se aceptan «contactos» de Llull con los movimientos laicos de la época, pero se silencian probables influencias. Se habla de la posible relación de Llull con el joaquinismo, los espirituales y otras sectas; pero, a reglón seguido, se afirma que se aparta de ellas en la medida en que éstas se iban alejando de la Iglesia.

En una segunda fase, los comentaristas ${ }^{60}$ ponen de manifiesto la polisemia del reformismo medieval, dentro del cual el reformismo luliano adquiere un sentido peculiar. Estos autores sustituyen, por su poca precisión, el concepto de «contactos» por el de «coincidencias» semánticas, «semejanzas» contextuales o «influencias» ideológicas. Coincidencias entre Llull y los reformadores medievales en la obsesión por transformar la desviada vida eclesiástica. Coincidencias entre LLull y los espirituales del círculo siciliano por reactivas un programa de instrucción popular. Semejanzas, dentro del círculo del infante Felipe de Mallorca, entre los sermones mallorquines de

59 Carreras Artau, o.c. M. Batllori, Ramon Llull en el món del seu temps, Barcelona, R. Dalmau, 1960.

60 Oliver, o.c. (1965). F. Domínguez, «Introducción», en ROL, XV, Turnhout, 1965. P. Ramis, Lectura del «Liber de civitate mundi» de Ramón Llull, Barcelona, PPU, 1992. 
la Summa de Llull y un grupo insular beguino. Influencias, en el momento de redactar el Blanquerna, entre LLull y los movimientos implicados en transformar la Iglesia.

Mientras para Oliver el reformismo luliano, al amparo del pauperismo, apocalipticismo y franciscanismo, hace de la pobreza la clave de toda reforma, para Domínguez no es más que una exigencia de la misión de conversión. La conversión de los musulmanes comporta de parte de los cristianos, no sólo un esquema de vida evangélicamente puro, sino también una adhesión a los ideales misioneros.

En una tercera fase ${ }^{61}$ se ha intentado descubrir la lógica interna del reformismo luliano y establecer la filosofía que sustenta su significación.

Servera, atendiendo al discurso utópico subyacente en el Blanquerna, esboza una filosofía de la historia ajustada al contexto reformista de la época. En esta filosofía la utopía luliana ha de entenderse como el rebasamiento, apoyándose en la espiritualidad del cristianismo apostólico, de la crisis presente. El pentecostesismo apostólico (don de lenguas y ciencia infusa) da paso en Llull a un racionalismo de orden táctico (colegio de lenguas y ciencia teológica) que, al reivindicar una demostración afirmativa de la fe cristiana, la aleja del racionalismo negativo dominicano de la Summa contra gentes de santo Tomás y del Pugio fidei de Ramon Martí, más interesado en probar el error de los no cristianos que la fe de los creyentes.

Sin descartar del todo el historicismo pentecostesista, debemos pensar en un reformismo asentado en el ejemplarismo metafísico, más acorde, además, con todo el pensamiento luliano del Arte, según el cual el cognoscere Deum implica un vivificare virtutes y un mortificare vitia.

La idea de que el desconocimiento de Dios es la raíz de la perversión del mundo está implícita en toda la obra de Llull y coincide con la primera síntesis luliana del eremitismo pedagógico y de la apologética artística. La novedad en las obras del último Llull radica en que la duda dogmática ha llegado a adueñarse incluso del eremita, oasis de sabiduría cristiana y de vida ejemplar en las obras del primer Llull. En el De civitate mundi Llull no sólo no se contenta en fijar la causa perversionis, sino que también, a través del análisis de las dignidades divinas, descubre una nómina de actos pervertidos (desconocimiento de la convertibilidad recíproca de las dignidades, negación del dimittere credere pro intelligere, olvido de la ciencia de la amancia, desviación de la teología de la mayor perfección).

Una ciudad en la que se ha invertido el orden establecido por Dios debe ser severamente castigada por la justicia divina. Sin embargo, esta doctrina luliana de la condenación no coincide con la teoría de la «venganza escatológica» propugnada por ciertas tendencias greco-cristianas. En Llull la escatología punitiva es superada por la acción salvífica y condenatoria de Dios como modalidad de su misma acción arquetípica. Si Dios ha producido el mundo a semejanza de las dignidades, también lo restaura en aplicación de esas mismas dignidades. Éste es el sentido profundo del reformismo metafísico luliano. A causa de la recíproca convertibilidad de las dignidades divinas, la acción arquetípica se complica con la acción salvífica.

61 V. Servera, «Utopie et histoire. Les postulats théoriques de la praxis missionnaire», en «Raymond Lulle et le Pays d'Oc», Cahiers de Fanjeaux, 22 (1987), pp. 191-228. S. Trías Mercant, «Prólogo», en Ramis, o.c. 


\section{MONTPELLIER, CLAVE EN LA FORMACIÓN CIENTÍFICA DE LLULL}

La investigación actual se decanta cada día más por Montpellier como centro neurálgico de la formación científica de Ramón Llull. Esta postura viene avalada por una serie de circunstancias: Llull consiguió en Montpellier la aprobación de sus obras y la autorización real para la fundación de Miramar. En Montpellier pudo vivir el cosmopolitismo de la ciudad y acercarse al pensamiento judío a través de sus sinagogas. Montpellier era, además, un centro cultural de primer orden con importantes escuelas de medicina, de derecho y, aunque menos relevantes, de artes y de teología. Montpellier poseía una floreciente tradición religiosa y eclesiástica, alentada por dominicos y franciscanos.

Algunos lulistas consideran que en esta parte del reino de Mallorca nace el Llull polígrafo, ${ }^{62}$ ya que en esta ciudad estudia medicina, derecho, filosofía, teología, además de lógica y gramática. $^{63}$

Otros lulistas piensan que Montpellier aportó a Llull el contacto directo con la medicina, entendida como auténtica filosofía natural. ${ }^{64}$

El Montpellier del siglo XIII —cree Gayá— situó a Llull en el centro de una doble revolución científica. La institucionalización universitaria implicaba la negación de los personalismos científicos y, a la vez, la negación de la experiencia vulgar, y favorecía, en cambio, un empirismo teorizado. Se trataba de formular el ideal de una medicina interesada en armonizar la práctica y la teoría, rescatando la antropología del exclusivismo filosófico y rescatando la experimentación médica de los acostumbrados recetarios. Importa construir —afirma Gayá - una theorica medicinae a partir de la cual el experimentum pierde su carácter anecdótico y acumulativo para ser integrado en el proceso científico como elemento discursivo crítico.

Michela Pereira afirma que el interés de Llull por la medicina debe entenderse desde la perspectiva de sus preocupaciones teológicas. Recogiendo las indicaciones de F.A. Yates (1954) y de Pring-Mill (1961) considera que Llull, antes de la redacción de los Libri principiorum (1274), se dedicó probablemente en Montpellier a la lectura atenta de obras científicas, sobre todo médicas, no para convertirse en un médico, sino para buscar una base científica a la apologética, orientada a los sabios y doctos musulmanes y judíos.

Desde este supuesto concreta Pereira que, mientras Llull suele silenciar el nombre de los autores en quienes se inspira, hace mención muchas veces de aquellos con quienes polemiza. Tal sucede en el Liber principiorum medicinae (1274) al referirse a aquellos que pudo conocer en Montpellier, como Pedro Hispano, Avicena y los médicos salernianos Mateo Plateario y Constantin Africano ${ }^{65}$ Llull pudo conocer textos de Avicena y de Aristóteles, ya que en los años de su estancia en Montpellier el Corpus Toletanum, con obras de filosofía natural aristotélica, y el Canon de Avicena, la más madura sistematización de la ciencia médica hipocrático-galénica, sustituían en las

62 A. Soria, ROL, III, 1961-63, p. 19.

63 Garcías Palou, o.c., p. 103.

64 Gaya, «El ambiente científico de Montpellier en los siglos XIII y XIV», pp. 59-67. Pereira, o.c.

65 Pereira, o.c., pp. 23-26. 
escuelas de medicina al viejo corpus médico recogido en la Articella. ${ }^{66}$ Sin embargo, las vinculaciones con la escuela médica de Salerno son claramente indirectas, así como también las coincidencias averroistas respecto de la teoría de los grados de los elementos y de los humores.

Llinarés ofrece una tercera versión del Montpellier científico luliano, al diferenciar entre el antes (1275-1289) y el después (1290-1312) de las correcciones al Arte, iniciadas a partir de la Ars inventiva veritatis (1290).

Para Llinarés, que olvida en este caso el tema de la medicina, ${ }^{67}$ el Montpellier anterior a la reforma del Arte representa un «tiempo de interrogantes». El año $1289-90$ es el año en que el Studium montpellieriano, bajo el impulso de Jaime II de Mallorca, se transforma en universidad ${ }^{68}$ y el año en que Llull empieza la reforma del Arte, escribiendo en aquella ciudad el Ars inventiva veritatis (1290). Llull imparte lecciones públicas, seguramente en el convento de los franciscanos, cosa que servirá para que Ramón Gaufredi, general de la orden, autorice la enseñanza de este Arte reformado en los conventos de la orden.

Se ha dicho que la reforma del Arte es su perfeccionamiento por reducción formal, pasando de una estructura cuaternaria a una construcción totalmente ternaria. Quizás sería mejor afirmar que Llull cayó en la cuenta del desequilibrio epistemológico que implicaba haber configurado el Arte sobre una doble base estructural. Mientras las figuras metafísico-teológicas seguían un modelo cuaternario, la figura «T» o figura lógica, fundamento formal del discurso, adopta una configuración ternaria y triangular desde un principio. La reforma sería el reajuste, además de la reducción, de todas las figuras cuaternarias al modelo ternario de la figura «T».

\author{
Maioricensis Schola Lullistica \\ Apartado 17 \\ Palma de Mallorca (España)
}

66 I. García Ballester, «Las influencias de la medicina islámica en la obra médica de Arnau de Vilanova», en $E l$ debat intercultural als segles XIII $i$ XIV.

67 A. Llinares, «Raymond Lulle à Montpellier. La refonte du Grand Art», en «Raymond Lulle et le Pays d"Oc», Cahiers de Fanjeaux, 22 (1987), pp. 19-24.

68 M. Bories, "Origines de l'Université de Montpellier», en Les universités de Languedoc aux XIII siècle, Toulouse, 1970. 